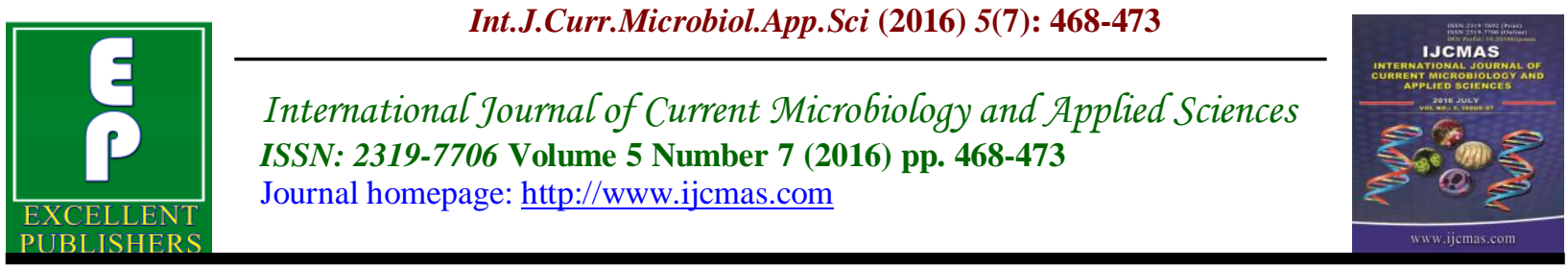

Original Research Article

http://dx.doi.org/10.20546/ijcmas.2016.507.050

\title{
Isolation and Antibiotic Susceptibility of Mycoplasma pneumoniae from Tonsillitis patients
}

\author{
Ibtisam H. Al-Azawi ${ }^{1}$, Ali A. Jwad ${ }^{2}$ and Ahmed R. AL- Imarah ${ }^{3}$ \\ ${ }^{1}$ Department of Medical Microbiology, College of Medicine, University of Al-Qadisiya, Iraq \\ ${ }^{2}$ Department of Surgery, College of Medicine, University of Al-Qadisiya, Iraq \\ ${ }^{3}$ Department of Medical Microbiology, College of Medicine, University of Al-Qadisiya, Iraq \\ *Corresponding author
}

\begin{abstract}
A B S T R A C T
Keywords

Mycoplasma pneumoniae, Commercial kits, Mycoplasma IH Modified Medium

\begin{tabular}{l}
\hline Article Info \\
\hline Accepted: \\
15 June 2016 \\
Available Online: \\
10 July 2016
\end{tabular}

Mycoplasmas have been implicated in a variety clinical condition. However, our result determine only certain Mycoplasma pneumonia are disease associated with tonsils core and surfaces in patient range 3- 30 years ages. The result was depending on culture methods by using IH-modified medium. Nine of antimicrobial agent from commercial (Mycoplasma system plus) kits are available for the treatment of Mycoplasma pneumoniae infection in humans. The results was detected in $16.9 \%$ percentage patients, the existence of isolates was appear in core tonsil more than surface tonsil,, colonies appeared after (12-14) days at $\mathrm{pH}$ optimum 7.8, the majority of Mycoplasma pneumoniae were resistant highly percentage to macrolides like Azithromcin, Erytyromycin and Clarithyromcin, all the isolates of Mycoplasma pneumoniae were uniformly susceptible to Ofloxacin. In conclusion detection of Mycoplasma pneumoniae was possible by characteristic growth by IH-modified medium, and ofloxacin could be the drug of choice for Mycoplasma pneumoniae.
\end{abstract}

\section{Introduction}

Mycoplasma pneumoniae is a member of the family of Mycoplasmataceae and the order of Mycoplasmatales. M. pneumoniae was originally isolated from the sputum of a patient with primary atypical pneumoniae by Eaton, Meiklejohn and van Herick in 1944 and was hence termed as Eaton's agent or primary atypical pneumonia virus $(1,2)$. Mycoplasma pneumoniae and Chlamydophila pneumoniae seem to play a important role in causing the recurrences atypical bacterial infections in children undergoing tonsillectomy because of severely recurrent acute tonsillopharyngitis (3). Mycoplasmas are the smallest and simplest self-replicating bacteria without cell wall, These organisms are so fastidious and completely depend on host biosynthetic precursors. Their cells contain the minimum set of organelles essential for growth and replication; a plasma membrane, ribosome and a genome consisting of a doublestranded circular DNA molecule (4). In addition the culture methods are relatively insensitive, time consuming, expensive, labour intensive and limiting its usefulness for routine purposes $(5,6)$. 
Generally, focus of interest has been on antimicrobial resistance in $M$. pneumoniae. Macrolide resistance was had reported to germinate in Japan $(7,8)$. It is well established that $M$. pneumoniae developed macrolide resistance is strongly related to the mutations in $23 \mathrm{~S}$ rRNA,several potential transit mutations in the complete sequence of 23S rRNA; The likelihood of $M$. pneumoniae developing resistance to macrolides by this mechanism under natural status may be enhanced, since there is only a single rRNA operon in the $M$. pneumoniae genome (8).

Commercially prepared culture media currently available are used to for identification and antibiotic susceptibility include as diagnostic kits, such as MycoIST2 (bioMerieux), Mycoview (Ivagen) and Mycoplasma system plus from Mycoplasma International Mycoplasma, Liofilcheme Inc., Italy)(9).

According to knowledge's clinical studies on the organisms, in Iraq, a little information was available on global prevalence of Mycoplasma pneumoniae isolated from tonsillitis patients therefore, there is an increase demand to investigaten the prevalence of Mycoplasma pneumoniae; the aim of our research were, Detection of frequency M.pneumoniae from patient tonsillitis by modified culture Commertial diagnostic kits,, and determine the antibiotic susceptibility profiles of clinical isolates.

\section{Materials and Methods}

One hundred swabs were taken from surface and core tonsillitis patients who admitted to E.N.T. department of ALDiwanyia Teaching hospital in Al-Qadissyia province (Iraq), the age ranged, 3-30 years during a period between march 2015 and July 2015 to test for the presence of $M$. pneumoniae, Swab were placed in
Mycoplasma transport medium to maintain the swab wet and then putted in ice bag until be taken to the lab for bacteriology investigation.

The culture technique was prepared as 300 $\mu l$ from mycoplasma transport medium was cultured in IH modified medium and mycoplasma system plus kit (LioFilChem italy). IH modified medium consisted of pplo agar horse serum, yeast extract, glucose, supplemented with essential requirement for growing of this microorganism(11), antibacterial (Penicillin, Ceftriaxone and Meronem) and antifungal (Nystatin and Fluconazole) that inhibit of other bacteria and fungi, respectively, with optimum $\mathrm{pH}$ (7.8) it is also added,subsequently, inhibitors of for many organism mentioned (12). The culture was incubated at $37^{\circ} \mathrm{C}$ under anaerobic condition for 12-14 days, while mycoplasma system plus diagnostic kit was sealed within a sterile petri dish and incubated anaerobically at $37^{\circ} \mathrm{C}$ for 48 hours.

Mycolplasma System plus (LioFilChem italy) Commertial Kit as indicated by the manufacture observed for color changes at 24 and $48 \mathrm{~h}$. the strip contained nine antimicrobial susceptibility testing of M.pneumoniae which included Tetracycline (4-8 $\mu \mathrm{g} / \mathrm{ml})$, pefloxacin $(8-16$ $\mu \mathrm{g} / \mathrm{ml}), \quad \quad$ ofloxacin $(1-4 \quad \mu \mathrm{g} / \mathrm{ml})$, Doxycycline $(4-8 \mu \mathrm{g} / \mathrm{ml})$, Erythromycin $(8-16$ $\mu \mathrm{g} / \mathrm{ml})$, Clarithromycin(8-16 $\mu \mathrm{g} / \mathrm{ml})$, Minocycline(4-8 $\mu \mathrm{g} / \mathrm{ml})$, Clindamycin(4-8 $\mu \mathrm{g} / \mathrm{ml}), \quad$ Azithromycin(4-8 $\quad \mu \mathrm{g} / \mathrm{ml})$.the development or absence of red color on the relevant part of the strip provided an index of resistance or susceptibility to each antimicrobial agent, respectively.

\section{Result and Discussion}

IH-modified medium : Of the 100 patients studied which result as 165 positive culture, 
28/165(17 \%) were positive for M.pneumoniae in IH-modified medium the resulte showed were 12-14 days at $\mathrm{pH}$ optimum7.8.The colonies appeared with characteristic fried-egg morphology because the organisms pentrate deeply into the agar in the central region of the colony figure (1)

\section{Antimicrobial susceptibility patterns}

The fifteen isolates of M.pneumoniae were studied antibiotic susceptibility pattern by mycoplasma system plus kit as shown in figure(2).

The M.pneumoniae isolates fully (100\%) susceptible to Ofloxacin $(8 \mu \mathrm{g} / \mathrm{ml})$, Clindanmycin $(8 \mu \mathrm{g} / \mathrm{ml})$ and also The majority of M.pneumoniae isolates were susceptible to Pefloxacin $(16 \mu \mathrm{g} / \mathrm{ml})$, (93.33\%), Ofloxacin $(4 \mu \mathrm{g} / \mathrm{ml}),(86.67$ $\%)$, Minocycline $\quad(8 \quad \mu \mathrm{g} / \mathrm{ml})$ and Clindanmycin $(8 \mu \mathrm{g} / \mathrm{ml})$ as $(80 \%) .(66.67 \%)$ were sensitivity to Tetracycline $(8 \mu \mathrm{g} / \mathrm{ml})$,
Pefloxacin $(8 \mu \mathrm{g} / \mathrm{ml})$. (60\%) susceptible to Doxycycline $(8 \mu \mathrm{g} / \mathrm{ml})$. While in study the Tetracycline $(4 \mu \mathrm{g} / \mathrm{ml})$, Doxycycline (4 $\mu \mathrm{g} / \mathrm{ml})$ and Erythromycin $(8 \mu \mathrm{g} / \mathrm{ml})$ reported least susceptible $(40 \%),(6.67 \%)$, respectively.

Highly resistant (100\%) in this investigation recorded to Erythromycin $(4 \mu \mathrm{g} / \mathrm{ml})$, azithromycin and clarithromycin as shown in figure (3)

High efficacy and safety of macrolides as well as their use as an alternate therapy for penicillin-intolerant patients made them popular drugs. The wide use of these antibiotics led inevitably to the spread of the resistance strains. The two most common mechanisms of resistance are excretion of the drug from the cell and modification of the drug target site (13). The latter mechanism comes in the form of a sites pecific posttranscriptional modification of $23 \mathrm{~S}$ rRNA or mutations in $23 \mathrm{~S}$ rRNA or ribosomal proteins.

Fig.1 Colonies morphology of Mycoplasma pneumoniae grow Culture agar (IH- modified agar)

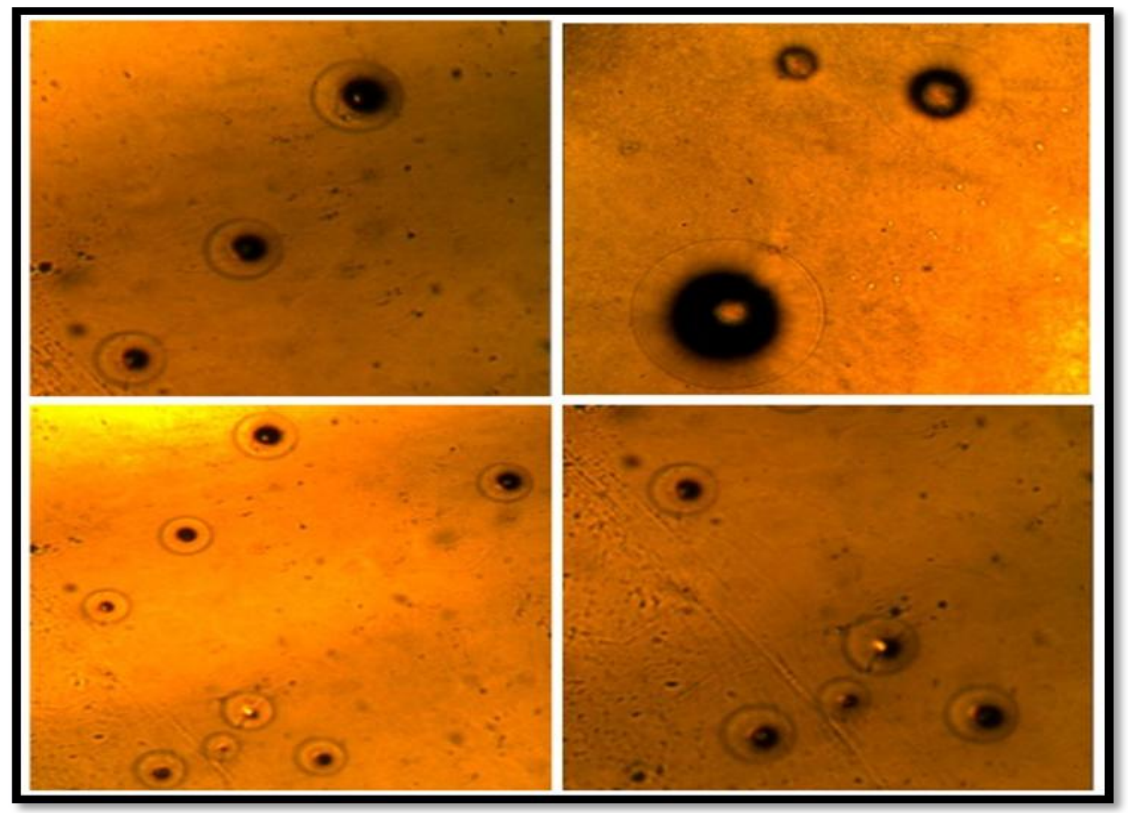


Fig.2 Mycoplasma system Plus kit for Antibiotic Susceptibility test for M.pneumoniae

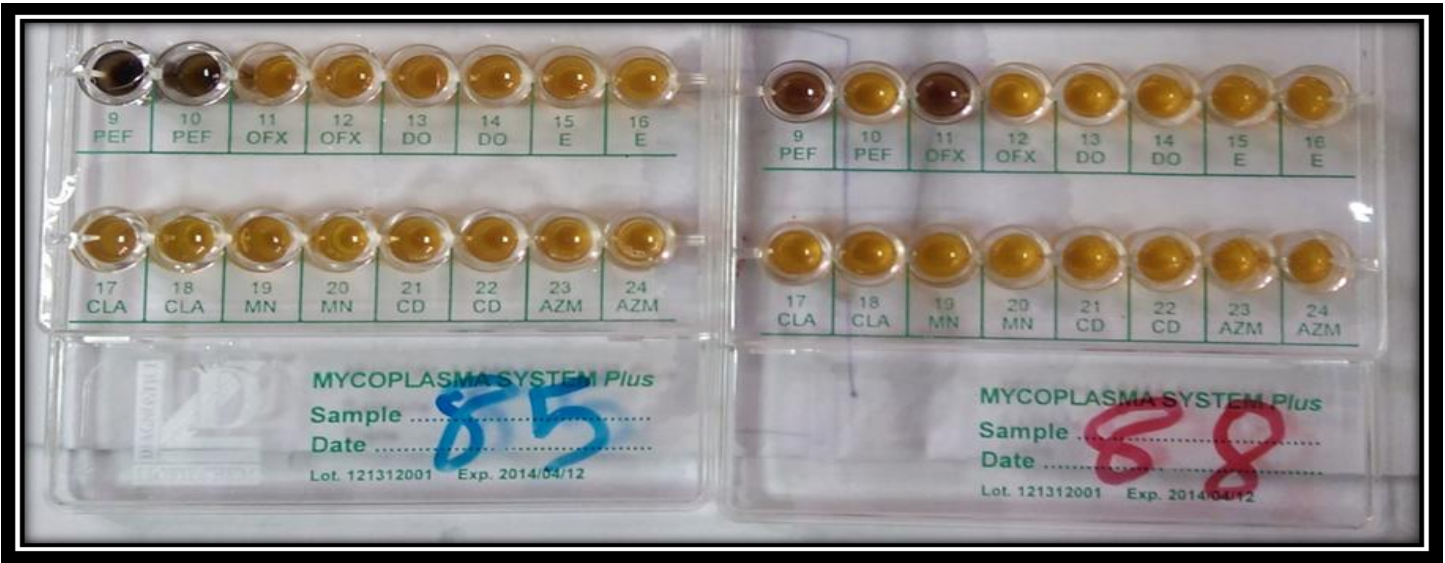

Fig.3 Results of M.pneumoniae antibiotic sensitivity test.

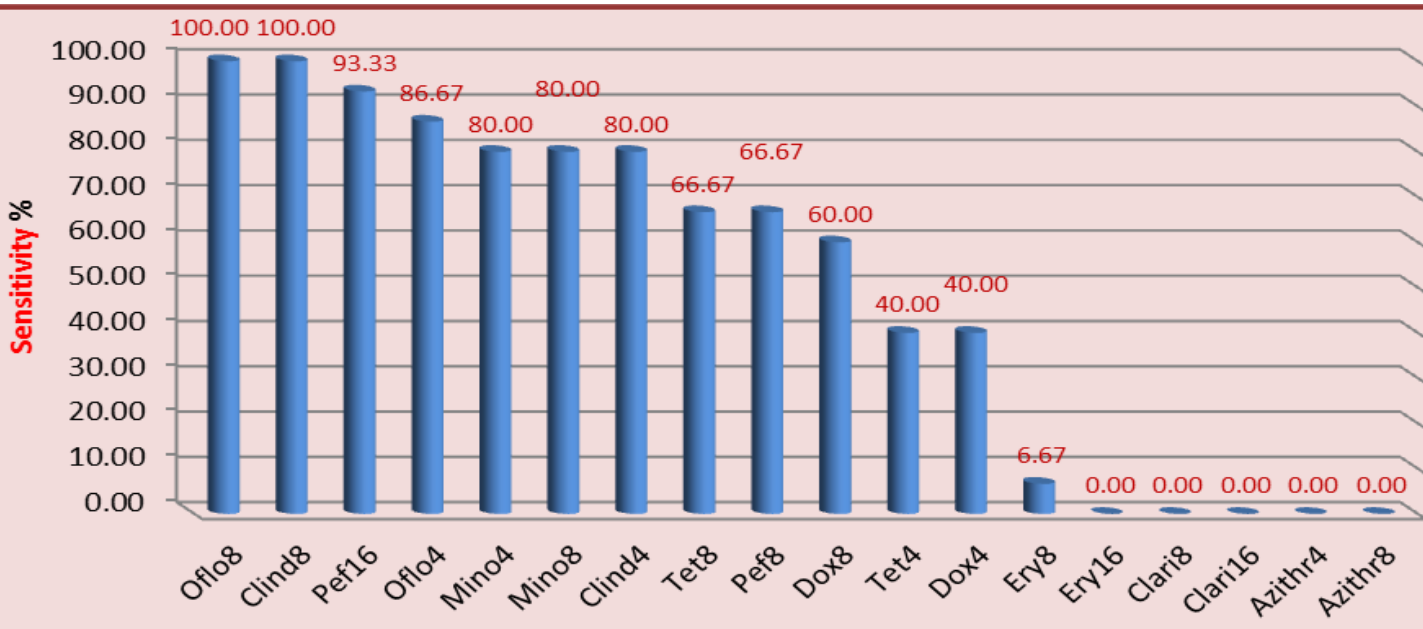

Fig.4 Distribution of patients groups according to age intervals

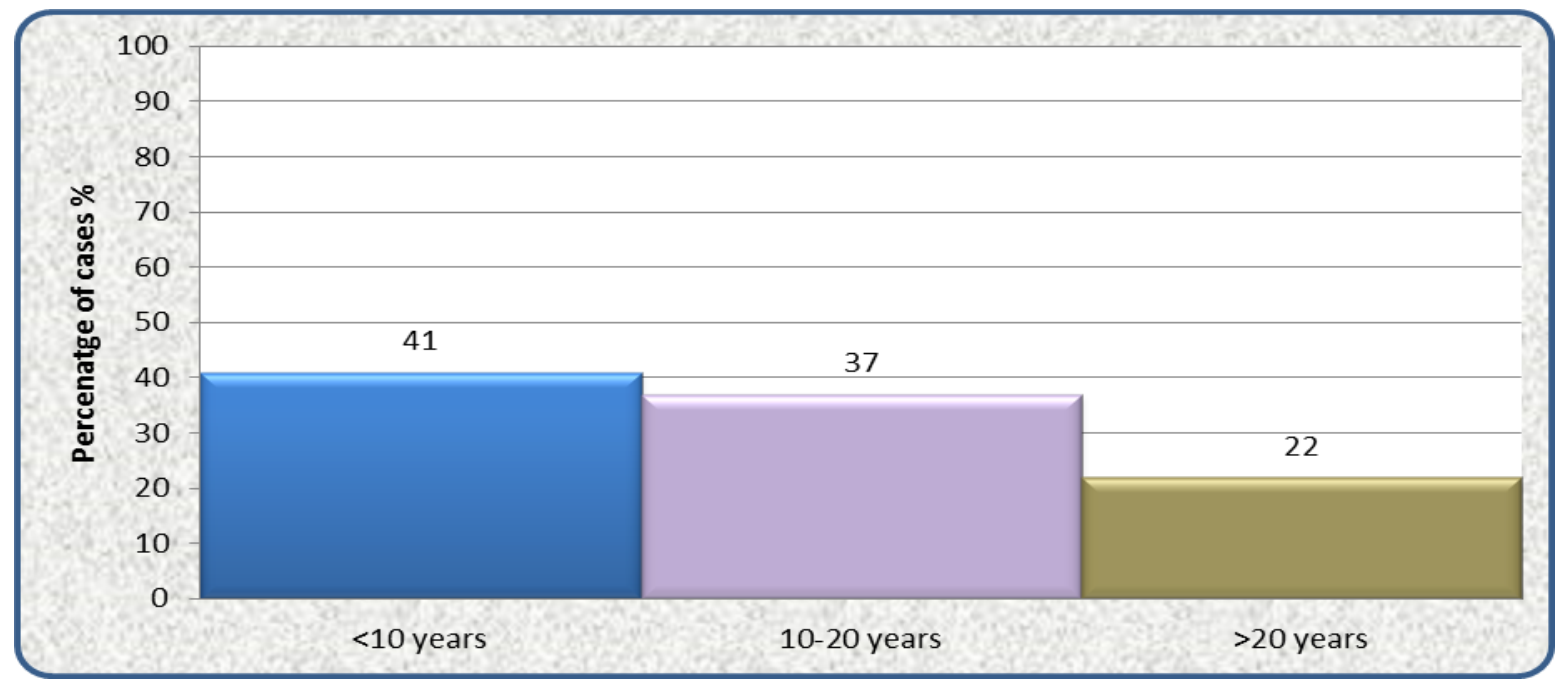


Mutations in protein L4 directly or allosterically affect macrolide binding and cause resistance by preventing drug binding to the ribosome (14). Mutations in another ribosomal protein, L22, do not significantly perturb drug affinity, but appear to act through an indirect mechanism. These mutants exhibit a wider opening of the tunnel so that the nascent peptide can apparently "slip by" the macrolide molecule bound in the tunnel (and/or possibly displace the drug) (15). Mutations in ribosomal protein genes are a frequent cause of drug resistance because a single mutational event is sufficient to render cells resistant to a macrolide. In contrast, resistance due to rRNA mutations is less common (16). Because of the multiplicity of rRNA genes in the majority of bacteria, the beneficiary (for the pathogen) effect of the mutation in one rRNA gene copy is usually masked by the abundance of wild type rRNA transcribed from unmutated gene copies. Therefore, this mechanism of resistance is more often found in the organisms with a low copy number of rRNA cistrons as Helicobater pylori that has two rRNA operons) (17).

The A2063G mutation has been found to be most prevalent in macrolide resistant M.pneumonia isolates, followed by the A2064G mutation; these mutations are associated with increased minimum inhibitory concentrations to macrolides (18). M.pneumoniae have been detected more frequently in the core of tonsils from surface There was no statistical difference in the distribution of patients groups according to age intervals as shown in figure(4)

The age group (1-10) are more prone to infection because of the lack of completeness and maturity of the immune system have and evolution in adults as well as the adults have acquired immunity as a result of their exposure to injuries in various stages of their lives as well as children are exposed to infection for various diseases such as influenza, measles and other diseases may lead to a weakened immune system against infections immune (19).

\section{Acknowledgment}

The authors thank the microbiology department of medicine college of AlQadissyia university, Iraq.

\section{References}

1.Eaton, M. D., Meiklejohn,G.; et al. (1944). "Studies on the Etiology of Primary Atypical Pneumonia : a Filterable Agent Transmissible to Cotton Rats, Hamsters, and Chick Embryos. J. Exp Med 79(6): 649-668.

2.Waites, K., Balish, M. and Atkinson, T. (2008). New insights into the pathogenesis and detection of Mycoplasma pneumoniae infections. Future Microbiol., 3(6): 635-648.

3.Esposito S.; Marchisio P.; Capaccio P.; Bellasio M.; Corti F.;Dusi E.(2010). Role of atypical bacteria in children undergoing tonsillectomy because of severely recurrent acute tonsillopharyngitis. Eur J. Clin Microbiol Infect Dis. ;27(12):1233-7

4.Naher H.S.1 and Said I.H.(2013). Culturing and PCR Methods for Detection of Mycoplasma hominis and Ureaplasma urealyticum in Women with Genitourinary Tract Infections. Int. Res. J. Medical Sci. 1(3), 25-29

6.She, R. C.; Thurber, A.; and Petti, C. A.(2010). Limited Utility of Culture for Mycoplasma pneumoniae and Chlamydophila pneumoniae for Diagnosis of Respiratory Tract Infections. J. Clin. Microbiol., 48(9): 3380-3382.

7.Morozumi M, Takahashi T, Ubukata K. (2010).Macrolide-resistant Mycoplasma 
pneumoniae: characteristics of isolates and clinical aspects of communityacquired pneumonia. J Infect Chemother; 16:78-86.

8.Bin C.,,a Chun-Jiang Z., Yu-Dong Y.,(2010).High Prevalence of Macrolide Resistance in Mycoplasma pneumoniae Isolates from Adult and Adolescent Patients with Respiratory Tract Infection in China. Clinical Infectious Diseases.51(2):189-194

9.Diaz, L.; Cabrera, L. E.; Fernandez, T.; Ibanez, I.; Torres, Y. and Obregon, Y. R.(2013). Frequency and Antimicrobial Sensitivity of Ureaplasma urealyticum and Mycoplasma hominis in pateints with vaginal Discharge. Medic. Review, 15(4): 45-53.

10.AL-Azawie, I. H. S. (2012). Cultural and Molecular Detection of Mycoplasmal Urogenital Infection in Women. Ph.D.Thesis, College of Medicine, University of Babylon,Iraq.

11.Ayyez, H.N.(2015).Molecular and Immunological study on Mycoplasma pneumoniae. Ph.D.Thesis, College of Medicine, University of Babylon, Iraq.

12.Stamm, B.; Moschopulos. M.; Hungerbuehler, H.; Guarner, J.; Genrich, G. L. and Zaki, S. R. (2008). Neuroinvasion by Mycoplasma pneumoniae in acute disseminated encephalomyelitis. Emerg. Infect. Dis, 14(4): 641-643.

13.Marne,G. and Alexander S. M. (2003).Macrolide Antibiotics: Binding Site, Mechanism of Action, Resistance. Current Topics in Medicinal Chemistry.3: 949-961.
14.Gregory, S.T.; Dahlberg, A.E.(2000). Erythromycin resistance mutations in ribosomal proteins L22 and L4 perturb the higher order structure of $23 \mathrm{~S}$ ribosomal RNA. J. Mol. Biol. 289: 827834

15.Gabashvili, I.S.; Gregory, S.T.; Valle, M.; Grassucci, R.; Worbs, M.; Wahl, M.C.; Dahlberg, A.E.; Frank, J.(2001). The polypeptide tunel system in the ribosome and its gating in erythromycin resistance mutants of L4 and L22. EMBO J. 8: 181-188.

16.Tait-Kamradt, A.; Davies, T.; Appelbaum, P.C.; Depardieu, F.; Courvalin, P.; Petitpas, J.; Wondrack, L.; Walker, A.; Jacobs, M.R.; Sutcliffe, J.(2002). Two new mechanisms of macrolide resistance in clinical strains of Streptococcus pneumoniae from Eastern Europe and North America. Antimicrob. Agents Chemother. 44:3395-3401.

17.Vester, B.; Douthwaite, S.(2001). Macrolide resistance conferrred by base substitutions in $23 \mathrm{~S}$ ribosomal RNA.Antimicrob. Agents Chemother., 45, (1):12- 13.

18.Zhao,F.;Liu,G.;Wu,J.,Cao,B.,Tao,X.,He,L., et al. (2013). Surveillance of macrolideresistant Mycoplasma pneumoniae in Beijing, China, from 2008 to 2012. Antimicrob. Agents Chemother. 57, 1521-1523.

19.Prescottb, L. M.; Harley, J. P. and Klein, D. A. (2010). Microbiology. 6th ed. McGraw. Hill companies Inc. New York.

\section{How to cite this article:}

Ibtisam H. Al-Azawi, Ali A. Jwad and Ahmed R. AL- Imarah. 2016. Isolation and Antibiotic Susceptibility of Mycoplasma pneumoniae from Tonsillitis patients. Int.J.Curr.Microbiol.App.Sci. 5(7): 468-473. doi: http://dx.doi.org/10.20546/ijcmas.2016.507.050 